\title{
Daylight distribution patterns in light wells in residential buildings in Penang, Malaysia
}

\author{
S. F. Syed Fadzil \& Z. A. Al-Absi \\ School of Housing, Building and Planning, \\ Universiti Sains Malaysia, Malaysia
}

\begin{abstract}
This paper focuses on the daylight distribution pattern in the light well in high rise residential buildings in Penang, Malaysia. Light well is a vertical void through all of the floors of a building which is designed to distribute daylight to adjacent spaces. The size of the light well is determined by the UBBL or the Malaysian Uniform Building By Laws (1984) clause no 40. The suitability of the clause is questioned when the original 8 storey residential buildings in the 1980s have risen up to 40 storeys after the year 2000. Eight case study buildings of varied heights and well sizes were carried out and natural illumination data were taken at well centres at each floor to be compared to the illumination outside. The percentage daylight factor $(\% \mathrm{DF})$ data were then calculated. The distinct pattern of daylight distribution from each case study was determined. The pattern of daylight factor values derived were found to be similar - very high illumination values at the top 3 floors; ample light for the next 4 to 5 floors while below those categories the light distribution were found to be quite low requiring artificial lighting almost 24 hours. However, this depends also on the $\mathrm{A} / \mathrm{H}$ (area/height) index ratios and on the design of well - whether all enclosed, with supplementary side openings or others. Computer simulations using Ecotect were carried out to compare the simulated daylighting pattern of the well to field work. The daylighting pattern was found to be similar with advantages to the simulated graphical outputs. Suggestions as to how light well designs can be improved especially in buildings under the bright Malaysian skies were concluded.
\end{abstract}

Keywords: daylight factor, light well, well index, residential building, highrise. 


\section{Introduction}

The development of high rise buildings which are either used for housing or commercial purposes are due to the rapid growth of urban population and increased income in the Southeast Asia. The demand for high-rise buildings continues to increase into the future. In Singapore, the number of high rise buildings has increased by three times in the last six years, while in Bangkok and Kuala Lumpur (KL) the number has doubled within the same period [1]. Most of these high rise buildings are used for housing, particularly in Singapore, Kuala Lumpur and Penang due to high population density [2].

Vertical housing can be categorized as low, mid and high rise in addition to super high rise (skyscraper). The low rise housing is defined as no more than four storeys, midrise ranging from five up to fifteen storeys, from sixteen to fifty is considered as high-rise and over fifty storeys is the skyscraper [3].

The light well is very popular in many high rises residential building design. The light well has become a significant architectural form over the past 30 years as it can help resolve many environmental issues. This is particularly true in deep plan commercial, office and residential buildings [4]. Architects and engineers have often used light well as a sustainable design strategy to achieve benefits such as passive cooling, ventilation and day lighting. Daylight use in a light well is particularly beneficial as the light well can allow natural light to reach potentially dark core areas which will reduce energy consumption from artificial lighting.

Light well is a vertical opening through floors of a building, designed to distribute daylight to adjacent spaces and usually located adjacent to vertical circulation [5]. Light well in high-rise housing is one of the subject matter that is not being researched upon resulting in dark and gloomy wells. In Malaysia, the light well is being determined by Malaysian Uniform Building By Law (1984) [6] clause 40 with the guidelines as listed in table 1 below:

Table 1: Light well dimension in buildings for natural lighting and natural ventilation according to UBBL.

\begin{tabular}{|l|l|c|}
\hline Space function & Building height & Minimum area of well \\
\hline Residential & 2 storeys of building height & $3.5 \mathrm{~m}^{2}$ \\
\cline { 2 - 3 } & 4 storeys of building height & $4 \mathrm{~m}^{2}$ \\
\cline { 2 - 3 } & 6 storeys of building height & $4.5 \mathrm{~m}^{2}$ \\
\cline { 2 - 3 } & 8 storeys of building height & $5 \mathrm{~m}^{2}$ \\
\cline { 2 - 3 } & More than 8 storeys of building height & $5.5 \mathrm{~m}^{2}$ \\
\hline
\end{tabular}

Furthermore, in Clause 39(4) (UBBL-1984) also states that "Each water closet, latrine, urinal or bathroom shall be provided with natural lighting and natural ventilation by means of one or more openings having a total area of not less than 0.2 square metres per water closet, urinal latrine or bathroom and such openings shall be capable of allowing a free uninterrupted passage of air."

The Malaysian building code requires the provision of an opening for bathroom, and other rooms too, to allow the natural ventilation and daylight to 
enter through the opening. These spaces can also have those openings towards the well and that would satisfy the by law. The problem faced is when there is insufficient daylighting at the well area - there will then be even much lesser daylight that would be able to penetrate the openings.

\section{Review}

According to Kotani et al. [7], the longer and narrower a light well is, the less efficient it becomes, while the larger and wider it is, the larger illuminance it provides. The best performance of the light well throughout the day is achieved when the sun is high in the sky and more light is being penetrated to the bottom of the light well [8]. Moreover, any means that lead and derived the daylight or sunlight inside the light well help to increase the occupants' satisfaction [7].

Kristl and Krainer [9] carried out illumination measurements and analyses, under an artificial sky, on a scale model of a deep ground-plan multi-storey apartment building that using light well as a source of daylight for the central areas. They used three innovative passive light well systems. The measurements showed that the best utilization of the available daylight is achieved when using light wells with wide upper opening and narrow lower part. The use of reflecting walls increase light penetration to the deep zones of the adjacent spaces. Similarly, Du and Sharples [10] stated that the average daylight factor could be improved by increasing the reflectance of well surfaces. Furthermore, they found that the solid well walls have a significant influence on the daylight levels in the adjoining rooms. A well with one-side room and three-side solid walls provide the highest daylight levels while a well with four-side rooms has the least daylight levels in the rooms.

Dawoud et al. [11] performed daylight measurements and simulation for a six-storey model light well. They found that using mirror-finished walls for the light well could improve the DF up to $100 \%$ for the lower floors as compared to matt white walls. Additionally, the simulation showed a good agreement with the measurements especially with the case of overcast sky comparing to the sunny sky. Kim and Kim [12] conducted a parametric measurements of illumination level in a scale model with various interior balcony configurations in a foursided atrium building. The results showed that adequate illumination level can be achieved for the position that is not covered by balcony as balcony clearly blocks more light from the skylight. Similarly, any means of projection inside the wells by the owners (i.e. air-conditionings' outdoor units, shadings or extensions) will result in obstruction of the light.

\section{Objectives and methods}

In this study, daylight illumination data is collected at various well indexes in residential buildings in Penang Malaysia. The objectives of the research are listed below:

1. To measure the extent of natural lighting levels experienced in these light wells from the top to the bottom. The eyes can detect that it is dark 
and gloomy in certain parts of the well and bright towards the top but no research has actually measured the extent of this illuminance.

2. To see whether there is a similar pattern of illumination from several wells of varied sizes and heights chosen for case studies taking into account their percentage daylight factor.

3. To carry out computer simulations to see if the same daylighting pattern prevails and to compare with the field work illumination patterns.

The research is of field work and experimental type. Several residential buildings with light wells were selected for data collection. Daylighting levels were taken from the middle of each light well at every floor to be compared to the outdoor illumination which was presumed to be constant during the measurement period. The measurements from each light well took approximately 20-30 minutes depending on the number of floors. Limitations occurred in only using buildings that were allowed access by their owners and management office and also limitations in the number of instruments available. The instrument used in this research is Extech Luxmeter with capable readings from 0-100,000 lux, shown in Fig. 1, and the data was then manually logged and recorded.

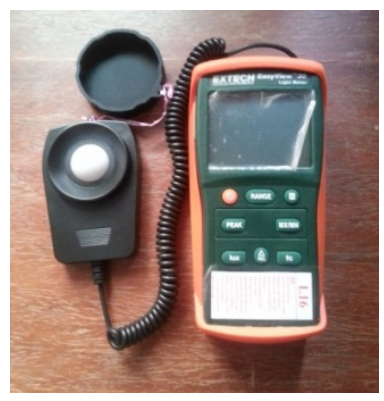

Figure 1: The Luxmeter Extech used in the study.

The case study buildings as can be seen in fig. 2 were 6 in numbers but the light wells studied were 8 as two of the buildings had 2 varied light well area and designs. In the case study buildings, it is noted that the light well at N Park is slightly different when the well is designed with some openings on the sides whereby supplementary day lighting can be received. The light well at N Park does not totally rely on the top illumination. The Centrio and Kheng Tian buildings have light wells that are not similar in their sizes or area. Data was collected in both different area light wells to see also if any significant difference is achieved from the 2 wells.

The light wells were varied in terms of their area - from as smallest at $2.7 \mathrm{~m}^{2}$ at Kheng Tian which did not fulfil the UBBL 40 but it was constructed before the implementation of the by law; to the biggest well at University Height with an area of $84.5 \mathrm{~m}^{2}$. The $\mathrm{A} / \mathrm{H}$ index which measures the ratios of well area (A) to its height $(\mathrm{H})$ is another important indicator especially in relation to the overall volume and proportion of the well. A number as low as 0.03 indicates a very 
small light well in relation to its height, while a ratio of 2.01 indicate a light well of a generous size. The residential buildings and their light well characteristics are listed below.

Table 2: $\quad$ Characteristics of the case study buildings with wells.

\begin{tabular}{|c|c|c|c|c|}
\hline Name & No. of storeys & Height $(\mathrm{H})$ & Well area $(\mathrm{A})$ & Index A/H \\
\hline \multirow{2}{*}{ Centrio } & 31 & $108 \mathrm{~m}$ & $8 \mathrm{~m}^{2}$ & 0.074 \\
\cline { 2 - 5 } & 31 & $108 \mathrm{~m}$ & $6.2 \mathrm{~m}^{2}$ & 0.057 \\
\hline N Park & 30 & $105 \mathrm{~m}$ & $22.4 \mathrm{~m}^{2}$ & 0.21 \\
\hline \multirow{2}{*}{ Kheng Tian } & 24 & $84 \mathrm{~m}$ & $8.5 \mathrm{~m}^{2}$ & 0.10 \\
\cline { 2 - 5 } & 24 & $84 \mathrm{~m}$ & $2.7 \mathrm{~m}^{2}$ & 0.032 \\
\hline Halaman Kenanga & 21 & $74 \mathrm{~m}$ & $14.8 \mathrm{~m}^{2}$ & 0.2 \\
\hline Symphony P & 20 & $71 \mathrm{~m}$ & $13 \mathrm{~m}^{2}$ & 0.18 \\
\hline Univ Height & 12 & $42 \mathrm{~m}$ & $84.5 \mathrm{~m}^{2}$ & 2.01 \\
\hline
\end{tabular}

Illumination data from all light wells were graphed and assessed in terms of their pattern. A simple high rise light well model ( $72 \mathrm{~m}$ in height) and $\left(16 \mathrm{~m}^{2}\right.$ in light well area) was then simulated using the software Ecotect to see whether the simulated data is similar to field work. The framework of methods used is given in Figure 3 and photos of case study buildings given in Figure 2.
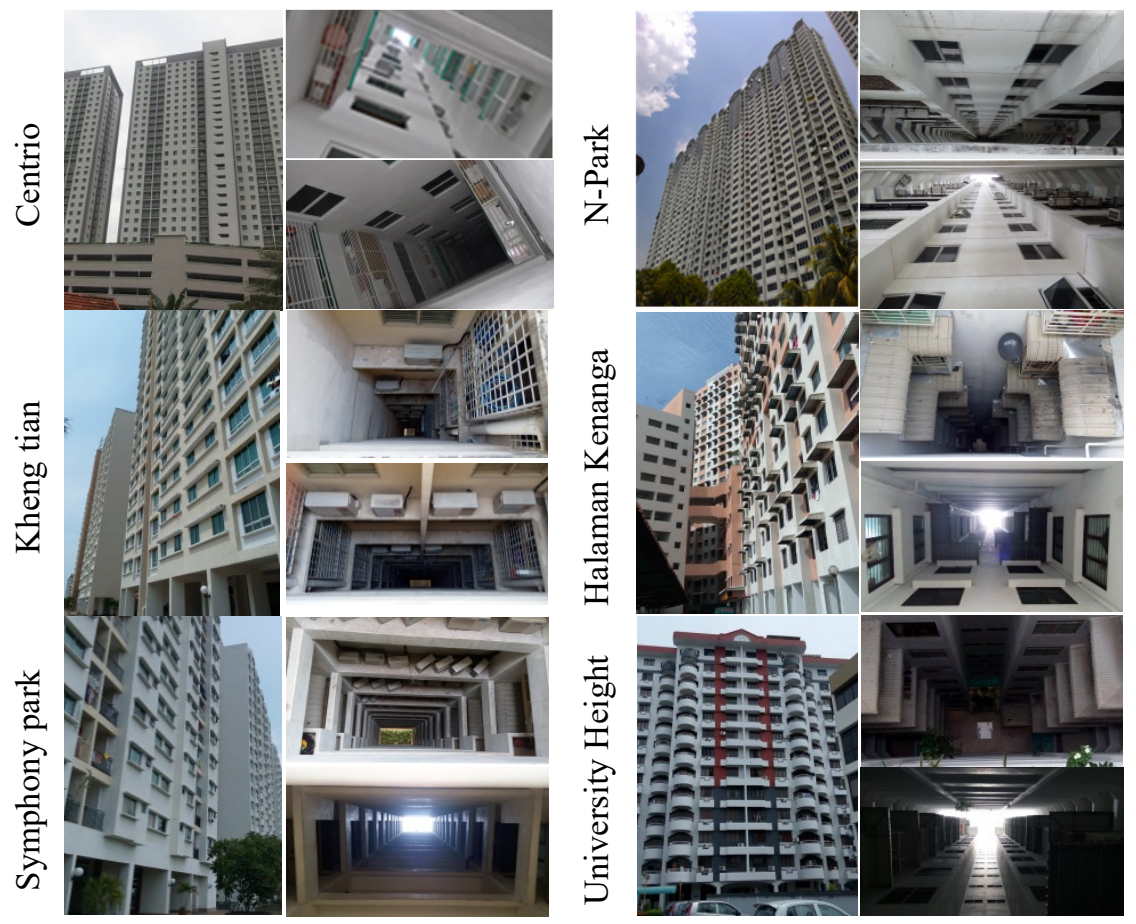

Figure 2: $\quad$ Case studies (the exterior views and through the light wells). 


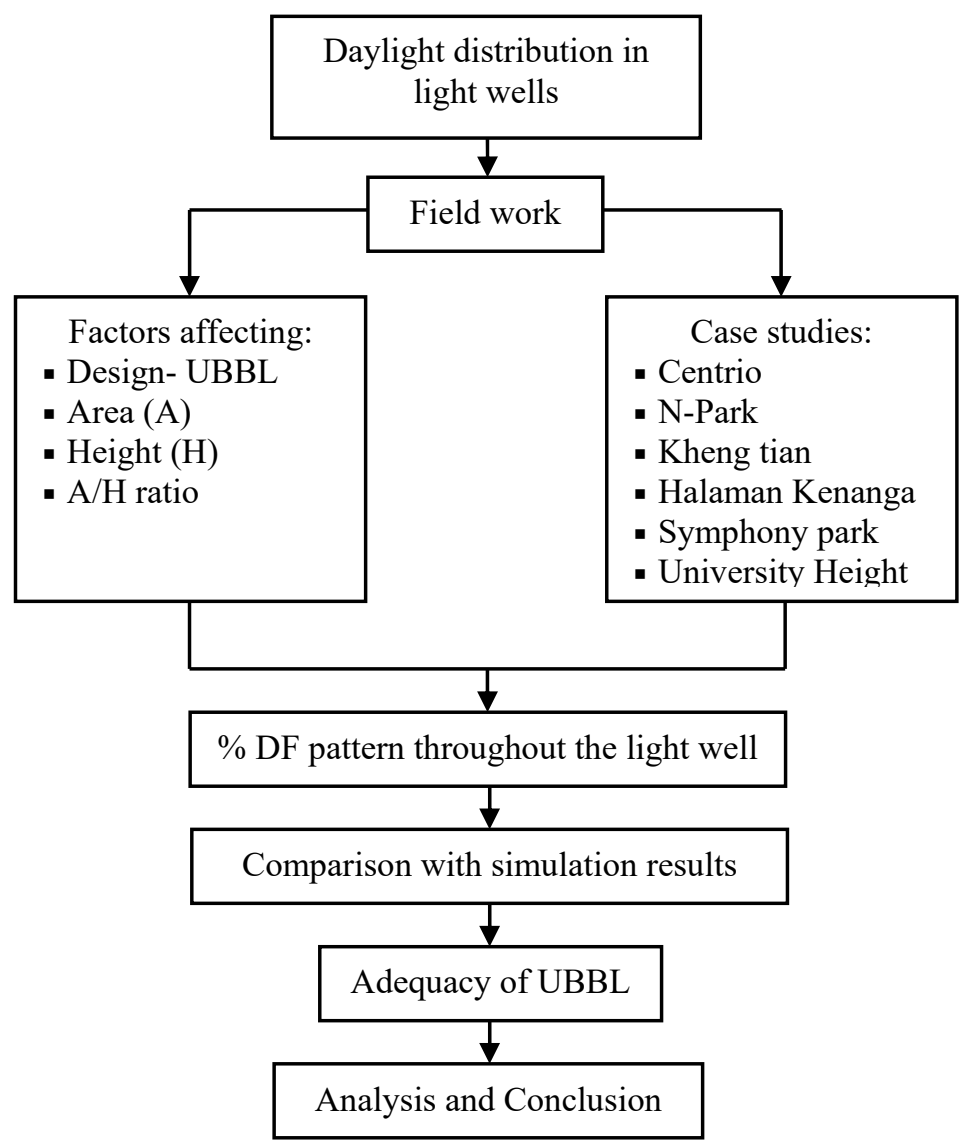

Figure 3: Methodology flowchart.

\section{Results/analysis}

Data for the illumination levels in percentage daylight factor (\%DF) for each light well is given in Table 3. From these data, the percentage daylight factors are graphed as can be seen in Fig. 4. The percentage daylight factor was chosen to be graphed instead of the absolute illuminance levels. The \%DF here is the ratio of light level at centre of well to the light level outside. This value is helpful in making quick comparisons of the relative daylight availability at various points in the well to the illumination outside [13]. All the light wells have similar pattern of daylight factor progressing exponentially from the bottom and as peaking up almost vertically it reaches the top where the openings are located which is the source of the daylight.

From Table 3, the top three floors of each buildings were found to be very brightly lit up to $40 \%$ daylight factor. $\mathrm{N}$ park is a unique case whereby the well is designed such that some supplementary daylight can be received. The drop in 
Table 3: Daylight factor (DF) at the centre of the light wells of the case study buildings.

\begin{tabular}{|c|c|c|c|c|c|c|c|c|}
\hline $\begin{array}{l}\text { Floor } \\
\text { level }\end{array}$ & $\begin{array}{c}\text { Centrio } \\
\text { (dark) }\end{array}$ & $\begin{array}{c}\text { Centrio } \\
\text { (light) }\end{array}$ & N Park & $\begin{array}{c}\text { K. Tian } \\
\text { (small) }\end{array}$ & $\begin{array}{c}\text { K. Tian } \\
\text { (Big) }\end{array}$ & $\begin{array}{c}\mathrm{H} . \\
\text { Kenanga }\end{array}$ & Sym. Park & U. Height \\
\hline 31 & 21.96 & 13.97 & & & & & & \\
\hline 30 & 5.26 & 3.71 & 42.44 & & & & & \\
\hline 29 & 2.89 & 1.24 & 26.96 & & & & & \\
\hline 28 & 1.51 & 1.13 & 16.94 & & & & & \\
\hline 27 & 0.63 & 0.89 & 12.02 & & & & & \\
\hline 26 & 0.39 & 0.59 & 9.15 & & & & & \\
\hline 25 & 0.20 & 0.76 & 7.90 & & & & & \\
\hline 24 & 0.15 & 0.89 & 7.14 & 9.57 & 16.13 & & & \\
\hline 23 & 0.15 & 0.93 & 6.51 & 2.65 & 4.41 & & & \\
\hline 22 & 0.10 & 0.85 & 6.35 & 1.11 & 1.76 & & & \\
\hline 21 & 0.06 & 0.60 & 5.99 & 0.60 & 0.86 & 29.33 & & \\
\hline 20 & 0.09 & 0.80 & 5.63 & 0.50 & 0.54 & 7.76 & 22.24 & \\
\hline 19 & 0.09 & 0.85 & 5.19 & 0.35 & 0.37 & 3.26 & 10.64 & \\
\hline 18 & 0.09 & 1.09 & 5.01 & 0.25 & 0.26 & 1.51 & 4.18 & \\
\hline 17 & 0.08 & 1.06 & 4.59 & 0.22 & 0.21 & 0.91 & 2.57 & \\
\hline 16 & 0.05 & 1.00 & 4.24 & 0.19 & 0.17 & 0.80 & 1.70 & \\
\hline 15 & 0.05 & 0.92 & 3.93 & 0.18 & 0.15 & 0.58 & 0.86 & \\
\hline 14 & 0.04 & 0.81 & 3.89 & 0.18 & 0.14 & 0.44 & 0.60 & \\
\hline 13 & 0.03 & 0.84 & 3.68 & 0.17 & 0.11 & 0.34 & 0.51 & \\
\hline 12 & 0.03 & 0.94 & 3.46 & 0.16 & 0.11 & 0.29 & 0.47 & 44.66 \\
\hline 11 & 0.04 & 0.76 & 3.23 & 0.15 & 0.09 & 0.28 & 0.32 & 23.11 \\
\hline 10 & 0.04 & 0.29 & 3.07 & 0.13 & 0.08 & 0.17 & 0.22 & 14.77 \\
\hline 9 & 0.03 & 0.29 & 3.00 & 0.12 & 0.07 & 0.14 & 0.20 & 9.90 \\
\hline 8 & 0.02 & 0.30 & 2.91 & 0.11 & 0.06 & 0.12 & 0.19 & 6.84 \\
\hline 7 & 0.02 & 0.34 & 2.84 & 0.15 & 0.08 & 0.10 & 0.14 & 4.82 \\
\hline 6 & 0.02 & 0.22 & 2.79 & 1.08 & 1.03 & 0.09 & 0.20 & 3.57 \\
\hline 5 & Car p. & Car p. & 2.67 & 2.33 & 1.48 & 0.09 & 0.95 & 2.74 \\
\hline 4 & Car p. & Car p. & 2.59 & Car p. & Car p. & 0.08 & Car p. & 2.03 \\
\hline 3 & Carp. & Carp. & 2.34 & Carp. & Car p. & 0.08 & Car p. & 1.68 \\
\hline 2 & Car p. & Car p. & 2.23 & Car p. & Car p. & 0.09 & Car p. & 1.36 \\
\hline 1 & Car p. & Carp. & 2.13 & Carp. & Car p. & 0.11 & Car p. & 1.19 \\
\hline 0 & Car $p$ & Car p. & 1.09 & Car p & $\mathrm{Ca}$ & 0.36 & Car p & 1.09 \\
\hline
\end{tabular}
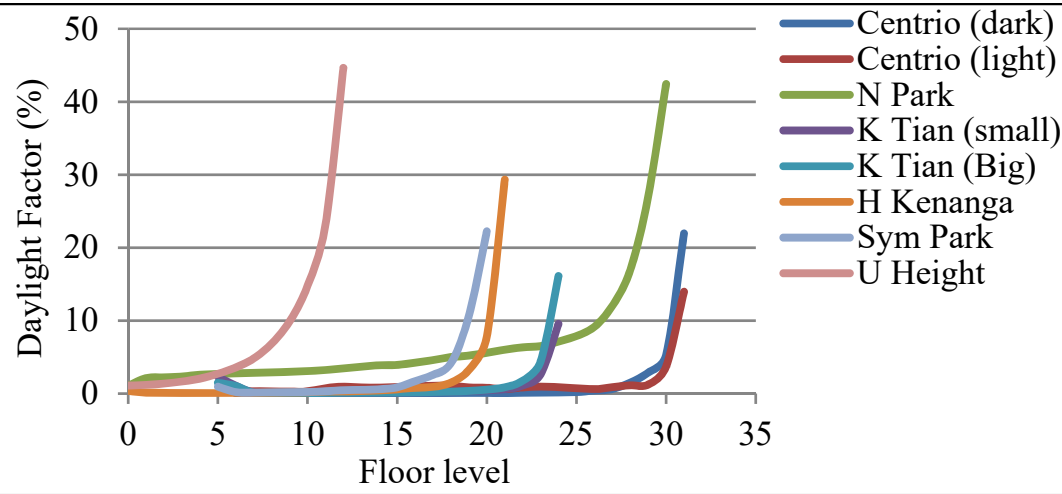

Figure 4: $\quad$ The $\% \mathrm{DF}$ values of each case study with respective floor levels. 
$\% \mathrm{DF}$ from the topmost floor to second and $3^{\text {rd }}$ highest floor is indeed very significant. Except for N Park and University Height, almost $80 \%$ of well's \%DF reading were below $1 \% \mathrm{DF}$ (in blue in Table 3 ) indicating a failure for the light to be transmitted from the top to the lower levels of the light well. This is especially when the well is designed at total centre of the building without any supplementary openings from the sides. The well at N Park was found to work well in terms of daylight with the design able to supplement light from the side. In the case of the University Height apartment - it is the index ratio that makes it acceptable in terms of daylighting.

In the simulation using the software Ecotect, a simple model of a high rise residential was constructed measuring $12 \times 12 \mathrm{~m}$ with light well at centre measuring $4 \times 4 \mathrm{~m}$ and a building height of $72 \mathrm{~m}$ as seen in fig. 5 . The climatic data of Penang was used and for the simulation, and well walls were regarded as near white reflectance values.
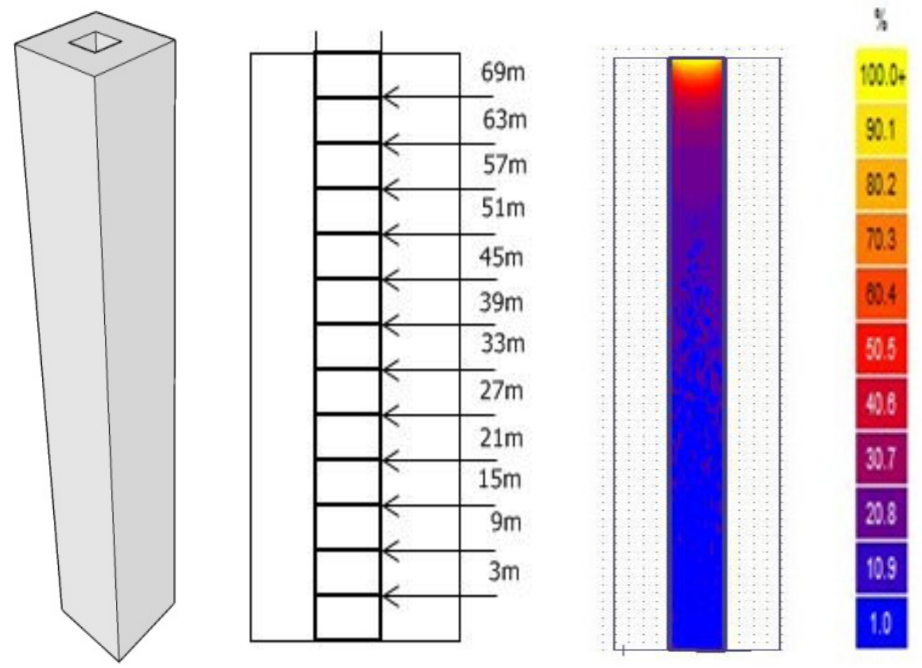

Figure 5: The simple Ecotect simulated model and the sectional result.

The illumination (in $\% \mathrm{DF}$ ) in the light well follows the field work data quite closely. The percentage DF is seen to be focused and maximized towards the top of the well, and as it gets lower the drastic drop can clearly be seen. The middle floors start to be bleak while the lowest 5 to 6 floors the simulation show that there is hardly any light or any difference to the light distribution. This is similar to the field work data where indications of very minimal values at the lower levels of the well resulted.

Graphics like the Ecotect simulation result shown in the building section are very useful as the bright and dark spots can clearly be seen and had the well require any redesigning, retrofitting with additional supplementary openings to it, simulations can help predict the results accurately before the real modification to the well even started. 


\section{Conclusions}

Light wells especially in high rise residential designs are excellent means of passive methods of building control when they can allow for both daylighting and natural ventilation to the building [14]. However there need to be guidelines as to their designs (rectangular/square/curvy etc.), the area of the well, the limits to how high they can get and also whether they are attached to openings which can supplement the light from the sides rather that totally relying from the top.

The UBBL 40 needs to be developed and based on scientific evidence. For now it is obvious that the clause that says for building more than 8 storeys - a minimum size of well of $5.5 \mathrm{~m}^{2}$ is considered satisfying the by law should be relooked into. In the Centrio building which is 31 storeys high and almost 4 times the 8 storey building specified in the by law, illumination level is found to be clearly insufficient.

Another problem that is found in these wells is that they have been made smaller in their original sizes through extensions and renovations made by residential unit owners [15]. These resulted in even darker wells. Wells are used also for the ventilation purposes and that is also another study that should be carried out. The best would be to find the optimum requirements of well design in high rise that would effectively satisfy both the daylighting and natural ventilation requirements.

This paper only concluded that the requirements of UBBL 40 for light well design for daylighting purposes is insufficient when the buildings get to be a lot higher than the 8-storey building originally stipulated for. More research in the area is highly encouraged.

\section{Acknowledgements}

The authors would like to acknowledge the fundamental research grant scheme FRGS no. 203/ppbgn/6711298 and the Universiti Sains Malaysia for funding the research.

\section{References}

[1] P. Rimmer and H. Dick, The City in Southeast Asia. NUS Press, 2009.

[2] B. Yuen and A. G. O. Yeh, High-Rise Living in Asian Cities, vol. 53, no. 9. Springer Science \& Business Media, 2011.

[3] J. Goody, R. Chandler, J. Clancy, D. Dixon, and G. Wooding, Building type basics for housing, Second ed. John Wiley \& Sons, 2010.

[4] T. Huang, H. Hocheng, T. Chou, and W. Yang, "Bring free light to buildings : overview of daylighting system," pp. 639-648, 2013.

[5] M. Kroelinger, “Toplighting Strategies," Spring, 2006.

[6] Uniform Building By-Laws 1984, 14th ed. MDC Publishers Sdn Bhd, 2006. 
[7] H. Kotani, R. Satoh, and T. Yamanaka, "Natural ventilation of light well in high-rise apartment building," Energy Build., vol. 35, no. 4, pp. 427434, 2003.

[8] A. A. Y. Freewan, A. A. Gharaibeh, and M. M. Jamhawi, "Improving daylight performance of light wells in residential buildings: Nourishing compact sustainable urban form," Sustain. Cities Soc., vol. 13, pp. 32-40, 2014.

[9] Ž. Kristl and A. Krainer, "Light Wells in Residential Building As a Complementary Daylight Source," Sol. Energy, vol. 65, no. 3, pp. 197206, 1999.

[10] J. Du and S. Sharples, "Assessing and predicting average daylight factors of adjoining spaces in atrium buildings under overcast sky," Build. Environ., vol. 46, no. 11, pp. 2142-2152, 2011.

[11] B. Dawoud, E. Amer, and D. Gross, "Experimental investigation of an adsorptive thermal energy storage," Int. J. energy Res., vol. 31, August, pp. 135-147, 2007.

[12] G. Kim and J. T. Kim, "Luminous impact of balcony floor at atrium spaces with different well geometries," Build. Environ., vol. 45, no. 2, pp. 304-310, 2010.

[13] S. F. Syed Fadzil, W.M. Harun and A. Abdullah. "A Method to Determine a Single Point Percentage Daylight Factor (\%DF) Value from Field Work Data." Advances in Environmental Biology 9(4) March, pp. 39-42, 2015.

[14] S. F. Syed Fadzil and H. Byrd. Energy and Building Control Systems in the tropics. Monograph. Penerbit Universiti Sains 2011 97pp.

[15] S. F. Syed Fadzil, C. S.Yong and K. K. Yoong. "Daylight Distribution in Air Well in High Rise Housing: The Taman Kristal Case Study." International Journal for Housing Science Vol. 30 No. 3 pp. 173-181, 2006 IAHS. 